\title{
視覚的表現による非集計ロジットモデルの効用関数形の決定方法 \\ GRAPHICAL METHOD FOR DETERMINING FORMS OF UTILITY FUNCTIONS OF DISAGGREGATE LOGIT MODELS
}

\author{
冨田安夫*・林良嗣**・奥田隆明*** \\ By Yasuo TOMITA, Yoshitsugu HAYASHI and Takaaki OKUDA
}

\begin{abstract}
This paper introduces a procedure for plotting partial residuals for multinomial logit models. This provides a method for graphical determination of utility functions of disaggregate logit models which offers significant advantages over the established "black box" method. An empirical example is developed in the context of revealed dwelling type choices in the Nagoya metropolitan area which shows the usefulness of the method.

Keywords : partial residual, disaggregate logit model, graphical method
\end{abstract}

\section{1.はしがき}

非集計ロジットモデルは, 行動主体の選好や制約条件 等, 従来の集計的なモデルでは扱いきれないような要因 を考慮できることから, 交通および土地利用等の分野へ の多くの応用がなされるようになってきている.

このような非集計ロジットモデルへのニーズに対し て, モデルの推定のための計算機プログラムパッケージ も整備されてきている.しかしながら, それらは, モデ ルに含まれる効用関数の関数形を仮定した場合に，その パラメーターを求めるためのものであり, データに フィットする関数形を見つけ出すシステマティックな方 法は確立されていない. すなわち, 従来では, 効用関数 形として,たとえば, 線形関数, 対数線形関数, CES 関数などをアプリオリに与え, モデルの推定後に統計的 に検討することにより, その適否を判定する方法を用い るのが常である1). このように, 関数形のデータへの適 合性を視覚的に確認することなく, ブラックボックスの

* 正会員 工修 (財) 計量計画研究所 研究員 ( ₹162 新宿区市ヶ谷本村町 2-9)

** 正会員 工博 名古屋大学助教授 工学部土木工学科 ( テ464 名古屋市千種区不老町)

*** 学生会員 名古屋大学大学院 工学研究科 (同上)
まま関数形を適合させている.

こうした状況は, 非集計ロジットモデルの場合, モデ ル式自体がすでに非線形関数であること, また, 被説明 変数が離散的な確率変数であることから, 通常の線形回 帰モデルの場合のように容易に観測データを図上にプ ロットし，効用関数形を視覚的に決定することができな いことに主たる原因があると考えられる.

しかし, 近年, 統計学の分野において, 特別な二項口 ジットモデルに限定すれば, 効用関数の残差の定式化が なされ，これを用いた効用関数のグラフ化の方法 ${ }^{2), 3)}$ が 提案されている.

本研究では, この方法を応用して, 一般の非集計多項 ロジットモデルにも適用できる効用関数のグラフ化の方 法を開発し，これを実際に都市圈における住宅タイプ選 択モデルの推定へ適用した結果, 本方法の有効性が確か められたので，ここに報告するものである.

\section{2. 非集計ロジットモデルの効用関数の視覚的 表現方法}

\section{（1）手順の概要}

本章では, 以下の手順に従って非集計ロジットモデル の効用関数の残差を定式化し, こうして求められる残差 の推定值をプロットして, 効用関数をグラフ化する方法 
を示す.

(1) 非集計ロジットモデルのモデル式を変形し, 効用 関数を導く.

(2) 効用関数を線形式で近似した場合の残差を定式化 する.

(3) 観測值に基づく残差の推定式を求める.

(4) 残差の推定值をプロットすることにより, 効用関 数をグラフ化する.

本研究の特徵は以上の手順において, 従来, 二項ロジッ トモデルに限定されていたもの ${ }^{2)}$ を，次に示すように多 項ロジットモデルに拡張しているところにある.以下に, 各手順の内容を示す.

（2）モデル式の誘道

個人 $n$ が $m$ 個の選択肢の中から選択肢 $i(i=1, \cdots, m)$ を選択する確率 $P_{\text {in }}$ は次式のように表わされるものとす る.

$$
P_{i n}=\exp V_{i n} /\left(\exp V_{1 n}+\cdots+\exp V_{m n}\right) \cdot
$$

ここで， $P_{i n}$ ：個人 $n$ が選択肢 $i$ を選択する確率

$V_{i n}$ : 個人 $n$ にとっての選択肢 $i$ の効用のう ち観測可能な部分

また, 個人 $n$ の選択結果は, 個人 $n$ が選択肢 $i$ を選択 した場合 $Y_{i n}=1$, それ以外の場合には, $Y_{i n}=0$ と表わ されるものとする.

まず，式（1）を効用関数 $V_{i n}(i=1, \cdots, m)$ につい て整理するために，個人 $n$ が選択肢 $i$ 以外を選択する 確率を式（2）のように表わし，

$$
1-P_{i n}=\sum_{j \neq i} \exp V_{J n} /\left(\exp V_{1 n}+\cdots \cdots+\exp V_{m n}\right)
$$

式（1）を式（2）で割り，両辺とも対数をとれば, 次 式のように変形できる.

$$
\ln \left\{P_{t n} /\left(1-P_{i n}\right)\right\}=V_{t n}-\ln \left(\sum_{j \neq i} \exp V_{j n}\right)
$$

いま, 便宜上, 効用関数 $V_{i n}$ は, 着目する変数 $X$ に 基づく効用 $g(X)$ と, それ以外の効用 $V_{\text {in }}^{\prime}$ によって表 わされるものとすれば,

$$
\ln \left\{P_{\iota n} /\left(1-P_{i n}\right)\right\}=g(X)+V_{i n}^{\prime}-\ln \left(\sum_{j \neq i} \exp V_{j n}\right)
$$

となる。

\section{（3）線形効用関数の場合の残差}

次に, 効用関数 $g(X)$ を線形関数 $\theta X(\theta$ : パラメ一 ター）で近似したとき, 選択確率 $P_{i n}$ がその近似值 $P_{i n}^{\prime}$ として表わされるものとすれば, 式 (4) は次式のよう になる。

$\ln \left\{P_{i n}^{\prime} /\left(1-P_{i n}^{\prime}\right)\right\}=\theta X+V_{i n}^{\prime}-\ln \left(\sum_{j \neq i} \exp V_{j n}\right) \cdots(5)$ したがって, 効用関数 $g(X)$ を線形関数 $\theta X$ で近似した ことによる残差 $r(X)$ は，式（4）から式（5）を差 し引くことにより次式となる.

$r(X)=g(X)-\theta X=\ln (Z)$
ここで, $Z=P_{i n}\left(1-P_{i n}^{\prime}\right) / P_{i n}^{\prime}\left(1-P_{i n}\right)$

式（6）をさらに簡単にするために, $\ln (Z)$ を $Z=1$ で テーラー展開し，その一次式により線形近似すれば次式 となる染1)

$$
\begin{aligned}
r(X) & \fallingdotseq P_{i n}\left(1-P_{i n}^{\prime}\right) / P_{i n}^{\prime}\left(1-P_{i n}\right)-1 \\
& =\left(P_{i n}-P_{i n}^{\prime}\right) / P_{i n}^{\prime}\left(1-P_{i n}\right) \cdots \cdots
\end{aligned}
$$

\section{（4）観測値に基づく残差の推定}

ここでは, 式（7）の残差 $r(X)$ を観測值に基づい て推定する. 式 $(7)$ の $P_{i n}$ は個人 $n$ が選択肢 $i$ を選 択する確率であり，これは観測できないため， $P_{i n}$ とし ては個人 $n$ の選択結果 $Y_{i n}(=0$ or 1$)$ を代入すること により,式（８）に示すような残差 $r(X)$ の近似值 $r^{\prime}(X)$ を求める.

$$
r^{\prime}(X)=\left(Y_{\text {in }}-P_{\text {in }}^{\prime}\right) / P_{\text {tn }}^{\prime}\left(1-P_{\text {in }}^{\prime}\right) \cdot
$$

ただし，式（7）の分母の $\left(1-P_{i n}\right)$ としては, 分母が ゼロとなることを避けるため，その近似值として（1$P_{\text {in }}^{\prime}$ をを用いている.

ところで,このようにして求められる $r^{\prime}(X)$ の期待 值 $E\left(r^{\prime}(X)\right)$ をとると，これが残差 $r(X)$ と一致する. すなわち,

$$
\begin{aligned}
E & \left(r^{\prime}(X)\right) \\
& =E\left\{\left(Y_{i n}-P_{i n}^{\prime}\right) / P_{\text {in }}^{\prime}\left(1-P_{i n}^{\prime}\right)\right\} \\
& =\left(E\left(Y_{i n}\right)-P_{i n}^{\prime}\right) / P_{\text {in }}^{\prime}\left(1-P_{i n}^{\prime}\right)
\end{aligned}
$$

ここで, 個人 $n$ の選択結果 $Y_{i n}$ の期待値 $E\left(Y_{i n}\right)$ は, $P_{i n}$ の不偏推定値であることは明らかであるため, 式

\section{(9) は}

$$
\begin{aligned}
& E\left(r^{\prime}(X)\right) \\
& \quad=\left(P_{\text {in }}-P_{\text {in }}^{\prime}\right) / P_{i n}^{\prime}\left(1-P_{\text {in }}^{\prime}\right)
\end{aligned}
$$

となる. 式（7）と式（10）を比較すれば, $P_{i n} \doteqdot P_{\text {in }}^{\prime}$ であることより, $r(X) \fallingdotseq E\left(r^{\prime}(X)\right)$ となる礼2 .

\section{（5） 効用関数のグラフ化}

以上より，個人 $n$ の選択結果 $Y_{\iota n}$ を用いて求められ る残差の近似値 $r^{\prime}(X)$ の期待値 $E\left(r^{\prime}(X)\right)$ は, 残差 $r$ $(X)$ と一致する. したがって, 効用関数 $g(X)$ のグラ フとしては, 線形関数 $\theta X$ に残差 $E\left(r^{\prime}(X)\right)$ を加えた $g(X)=\theta X+E\left(r^{\prime}(X)\right)$ を描けばよいことになる.

以上の手順においては，効用関数の近似式として線形 関数を用いているが，他の関数形を用いることも可能で ある.よって，仮定した効用関数を逐次改善することに よって真の効用関数に近づけることができる.

なお，上記の手順では，効用関数の 1 変数に着目して

注 1） $P_{\text {ln }}^{\prime}$ は $P_{\text { }}$ の近似值であることから, $Z \doteqdot 1.0$ となる. よって $\ln (Z)$ を $Z=1.0$ でテーラー展開し，一次式によ り近似することが可能であり, $\ln (Z) \doteqdot Z-1$ となる.

注 2）後述するように，効用関数の近似式を逐次改善するこ とが可能であり， $P_{i n}^{\prime}$ を $P_{t n}$ に次第に近づけることがで きる.これによって, $E\left(r^{\prime}(X)\right)$ の $r(X)$ に対する近似 の程度も上昇させることができる. 
いるが, ロジットモデルの推定においては, 変数間の独 立性が成立するものと仮定されていることから，他の変 数についても同様にそれぞれの効用関数形を定めること ができる。

\section{3. 非集計ロジットモデルの効用関数形の決定 手順とその有効性の検討}

本章では，以上の考え方に基づいた非集計ロジットモ デルの効用関数形の決定手順を示すとともに，これを実 際に多項ロジットモデルの推定に適用することにより, 本方法の有効性について検討する.

ここでは, 多項ロジットモデルの適用例として, 林・ 富田 ${ }^{4}$ による住宅タイプ選択モデルを簡略化して用いて いる.このモデルは，世帯の住宅タイプ選択行動を多項 ロジットモデルを用いてモデル化したものである．すな わち, 住宅夕イプ $i$ の観測される効用が $V_{i}$ のとき, 住 宅夕イプ $i$ の選択確率 $P_{i}$ は次式となる.

$P_{i}=\exp V_{t} / \sum_{j} \exp V_{J}$

ここで，住宅タイプ $i$ としては，(1)持家・戸建，(2)持 家・中高層, (3)借家・戸建, (4)借家・中高層の 4 タイプ とし,また, 効用関数 $V\left(=\sum_{i} \theta_{i} X_{i}\right)$ の説明変数としては,

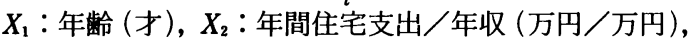
$X_{3}$ : 住宅の広さ $/$ 世帯人員（盢数／人）を用いている.

なお，データとしては昭和 53 年建設省住宅需要実態 調査のうち名古屋都市圏の住み替え世帯のデータ（サン プル数 692）を用いる.

以下， 4 つのステップに従って，モデルの効用関数形 の逐次改善を図る.

\section{step-1 線形効用関数を用いたパラメーター推定}

step-1 では，効用関数として線形関数を仮定して，最 尤推定法によりパラメーターを推定する.

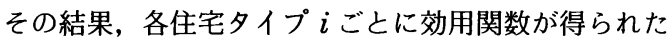
が，ここでは，持家・戸建を例として推定結果を示す。

$V_{1}=0.034 X_{1}-3.79 X_{2}+0.181 X_{3}+1.376$
(2.74)
(4. 34)
(5. 25)
(2.53)

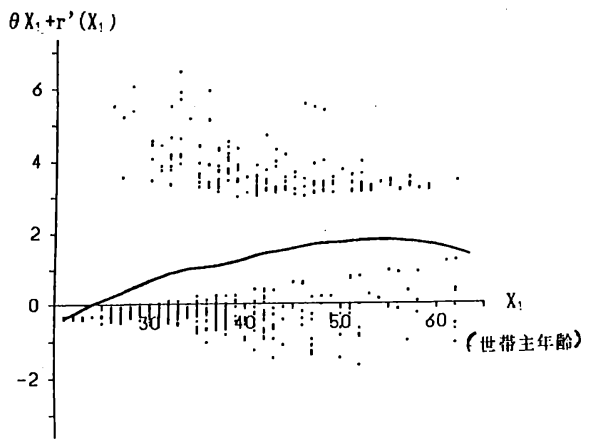

図-1＼cjkstart残差プロットと効用関数のグラフ化（1）
尤度比 $=0.271$, 的中率 $=48 \%,(）$ 内 : $t$ 值 step-2 残差の推定およびプロット

step-2 では, step-1 で推定されたモデルにより算定さ れる世帯 $n$ の住宅タイプ $i$ に対する選択確率 $P_{\text {in }}^{\prime}$ と, 実際に住宅夕イプ $i$ を選択した結果 $Y_{i n}$ とを式 $(8)$ に 代入し, 残差 $r^{\prime}(X)$ を求め, これを点 $\left(X, \theta X+r^{\prime}(X)\right)$ として $X Y$ 座標上にプロットする.

図一 1 は, 持家 · 戸建の効用関数 $V_{1}$ における変数 $X_{1}$ (=年㱓) について，この点をプロットしたものである.

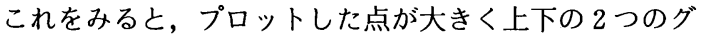
ループに分かれている.これは, $r^{\prime}(X)$ の算定において, 選択結果 $Y_{\text {in }}$ の值は 0 あるいは 1 であり, それが選択確 率 $P_{\text {in }}$ に対して過大であったり過小であったりするため である。

\section{step-3 効用関数のグラフ化}

step-3 では, step-2 でプロットした残差の近似值 $r^{\prime}$ ( $X)$ の期待值 $E\left(r^{\prime}(X)\right)$ をグラフ上で求め, 各 $X$ につ いて点 $\left(X, \theta X+E\left(r^{\prime}(X)\right)\right.$ を結びグラフ化する.この グラフは，2. で述べたように，線形関数に残差分を加 えたものであり, 効用関数 $g(X)$ を表わしている.

図一1 中の実線は，これを描いたものである泣3).これ

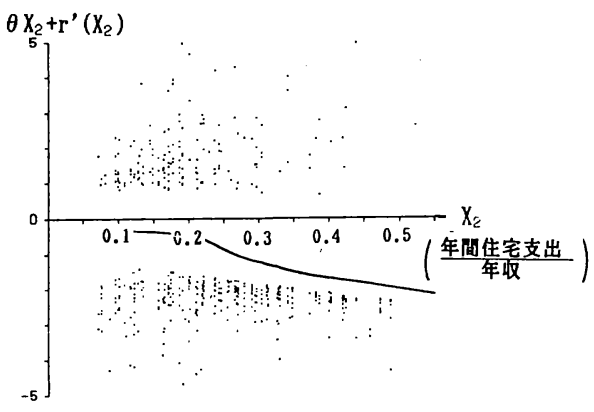

図-2 残差プロットと効用関数のグラフ化（2）

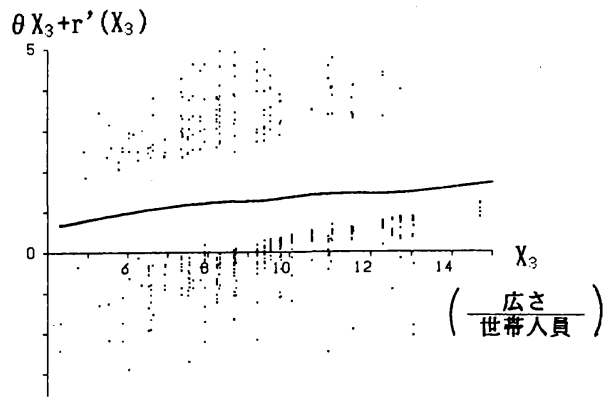

図一3 残差プロットと効用関数のグラフ化（3）

注 3）期待値の算定区間の設定によってグラフ形状は異なる が, ここでは, 変数に対する効用值の全体的傾向，すな わち,グラフ形状の滑らかさを損なわない限りにおいて, 区間を狭く設定している. 図一1 のグラフでは, 年齢 $X$ の期待值の算定区間を \pm 5 才とした. 
をみると, 効用関数は必ずしも線形関数とはいえず, 変 数 $X_{1}$ の増大に従って 55 才までは増加しており, 55 才 以降やや減少傾向を示している.

\section{step-4 効用関数形の決定と再推定}

最後のステップでは，図一1のグラフの性質を比較的 よく説明できる関数形を視覚的に判断し，この関数形を 用いて再びパラメーターを推定する.ここでは, 図一1 のグラフを表わす関数形として $X_{1}=55$ を軸とする二次 関数を用いた。

なお，図一2, 図一 3 は, 変数 $X_{2}, X_{3}$ について, 変数 $X_{1}$ と同様に, (step-2) および (step-3) を行った結果 である.これの視覚的な判断の結果, 変数 $X_{2}$ の関数形 としては， $X_{2}$ が 0.2 以下において定数であり，0.2 以 上において一次関数となる関数形を用い，また，変数 $X_{3}$ の関数形としては一次関数を用いることとする。

以上の関数形を用いて再推定した結果，次式を得た. $V_{1}=-0.003\left(\left(X_{1}\right)^{2} / 2-55 X_{1}\right)-4.176\left(X_{2}-0.2\right) \delta$
(3.86)
(2.97)

$+0.125 X_{3}-0.965$

(4.46) (2.03)

ここで, $\delta=0\left(X_{2} \leqq 0.2\right.$ のとき $), 1\left(X_{2}>0.2\right.$ のとき $)$

尤度比 $=0.283$, 的中率 $=52 \%,()$ 内 : $t$ 值

これをみると, 効用関数を線形関数から非線形関数に 修正することにより尤度比・的中率はともに上昇した。 特に, 的中率を持家・戸建の選択世帯についてみると, $49 \%$ から $57 \%$ へ上昇している. また, 非線形とした 変数 $X_{1}, X_{2}$ の係数の $t$ 值が有意なことからも, 効用関 数形を修正することにより，モデルの適合度は上昇した ものと判定できる.

さらに, 効用関数形を非線形に修正したことによる持 家・戸建の選択確率 $P_{1}$ への影響をみるために, 平均的

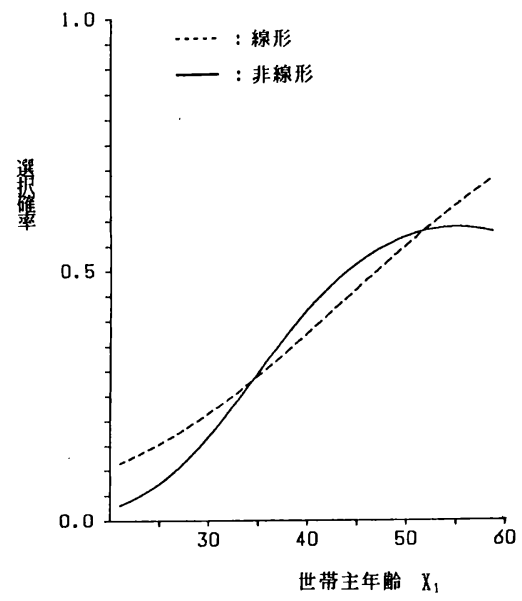

図一4 選択確率に及ぼす効用関数形の違いの影復
な世帯(世帯人員 3 人, 世帯年収 350 万円(S. 53 年価格)) を想定し， $X_{1}$ に対する持家・戸建の選択確率 $P_{1}$ を表わ すと，図一4の実線のようになった。これと破線で示さ れる線形関数の場合とを比較すると, 非線形の場合, 30 才から 50 才にかけて急激に選択確率が上昇し，50才以 降はほぼ一定であり，線形の場合に比べて現実の傾向を よく表わしているといえる.

\section{4. ま と め}

本研究において，一般の非集計多項ロジットモデルに も適用できる効用関数の視覚的表現の方法を示し，これ を名古屋都市圈における住宅タイプ選択モデルの推定に 適用し，本方法が有効であることを示した。

本方法の最も大きな特徴は, 視覚的に非集計多項口 ジットモデルの効用関数の関数形が確かめられることで あり，このことにより，以下のようないくつかの特徴も 有することとなる.

（1）効用関数として, 線形関数, 対数線形関数, $\mathrm{CES}$ 関数等の関数形を用いることの妥当性を視覚的に 確認できる.

（2）効用関数形を視覚的に決定できるため, 従来の ように複数の効用関数形について式行錯誤的にモデルを 推定することなく，効率的に適合度の高い関数形を選択 できる.

（３）従来においては, 連続変量でありながらカテゴ リー変数として扱われていたような変数についても, 連 続変数として表現できるため, モデルの感度が上昇する. また, 変数の数も減少を図ることができる.

（4）グラフ上にプロットされた残差により，特異 データのチェックを効率的に行うことができる.

最後に, 名古屋大学の河上省吾教授および本論文の査 読者の方々から，貴重なご意見を頂いた．ここに記して 感謝の意を表するものである.

\section{参 考 文 献}

1）森杉壽芳：非集計モデルの推定と検定，土木計画学講習 会テキスト, Vol. 15, pp. $44 \sim 46,1984$.

2) Landwehr, J. M. et al. : Graphical Methods for Assessing Logistic Regression Models, Journal of the American Statistical Association, Vol. 79, pp. 61 83, 1984.

3) William, S. C. : Robust Locally Weighted Regression and Smoothing Scatterplots, Journal of the American Statistical Association, Vol. 74, pp. 829 836, 1979.

4）林 良嗣・富田安夫：住み替え潜在需要・顕在化・住宅 タイプ選択・居住ゾーン選択のプロセスを組み込んだ住 宅需要・立地分析モデル, 土木計画学研究・講演集, No. 10, pp. 259 266, 1987.

(1988. 3.8 - 受付) 